\title{
Validity, Reliability and Sensitivity of a Volleyball Intermittent Endurance Test
}

\begin{tabular}{|r|l|}
\hline Journal: & International Journal of Sports Physiology and Performance \\
\hline Manuscript ID & Draft \\
\hline Manuscript Type: & Original Investigation \\
\hline Keywords: & field testing, intermittent exercise, volleyball performance \\
\hline \multicolumn{2}{|l}{} \\
\hline
\end{tabular}

\section{SCHOLARONE ${ }^{\text {M }}$ \\ Manuscripts}


1 Validity, Reliability and Sensitivity of a Volleyball Intermittent Endurance Test

2

3 Manuscript Type: Original Investigation

4

5

6 Jose A. Rodríguez-Marroyo ${ }^{1}$, Javier Medina-Carrillo ${ }^{1}$, Juan García-López ${ }^{1}$, Juan C.

7 Morante $^{1}$, José G. Villa ${ }^{1}$, Carl Foster ${ }^{2}$

8

$9{ }^{1}$ Department of Physical Education and Sports, Institute of Biomedicine (IBIOMED), 10 University of León, León, Spain.

$11{ }^{2}$ Department of Exercise and Sport Science, University of Wisconsin-La Crosse, La 12 Crosse, USA.

13

14 Correspondence:

15 Jose A. Rodríguez-Marroyo

16 Department of Physical Education and Sports

17 University of León

1827017 León, Spain

19 Phone +34 987293022 Fax +34 987293008

20 e-mail j.marroyo@unileon.es

22 Preferred Running Head: Endurance field test in volleyball

23 Abstract Word Count: 211

24 Text Only Word Count: 3101

25 Figures: 3

26 Tables: 2

27

28

29

30

31

32

33

34 


\section{Abstract}

37 Purpose: The purpose of this study was to analyze the concurrent and construct validity 38 of a volleyball intermittent endurance test (VIET). Moreover, its test-retest reliability and 39 sensitivity to assess seasonal changes was also studied. Methods: During the pre-season, 40 seventy one volleyball players of different competitive levels took part in this study. All 41 performed the VIET and a graded treadmill test with gas exchange measurement (GXT). 42 Thirty one of the players performed an additional VIET to analyze the test-retest 43 reliability. To test the sensitivity of VIET, 28 players repeated the VIET and GXT at the 44 end of their season. Results: Significant $(P<0.001)$ relationships between VIET distance 45 and $\mathrm{VO}_{2 \max }(r=0.74)$ and GXT maximal speed $(r=0.78)$ were observed. There was no 46 significant differences between the VIET performance test-retest $(1542.1 \pm 338.1 \mathrm{vs}$. $47 \quad 1567.1 \pm 358.2 \mathrm{~m})$. Significant $(P<0.001)$ relationships and ICC were found $(r=0.95$ 48 and ICC $=0.96)$ for VIET performance. VIET performance increased significantly $(P<$ $490.001)$ with players' performance level and was sensitive to fitness changes across the 50 season $(1458.8 \pm 343.5$ vs. $1581.1 \pm 334.0 \mathrm{~m}, P<0.01)$. Conclusion: This study suggests 51 that VIET may be considered as a valid, reliable and sensitive test to assess the aerobic 52 endurance in volleyball players.

53

54 Keywords: field testing, intermittent exercise, volleyball performance

55

56 


\section{Introduction}

Since Hill and Lupton ${ }^{1}$ introduced the concept of maximal oxygen uptake $\left(\mathrm{VO}_{2 \max }\right)$, the basics of its assessment have been established ${ }^{2}$ and its importance as a marker of fitness accepted, ${ }^{3}$ it has been routinely assessed in the sport science community. Moreover, the technological development of automated metabolic gas analysis systems has facilitated the wider assessment of $\mathrm{VO}_{2 \max }{ }^{4}$ The $\mathrm{VO}_{2 \max }$, together with efficiency/economy and the fractional utilization of the aerobic capacity, are the main parameters of the aerobic performance. ${ }^{5}$ Therefore, measurement of $\mathrm{VO}_{2 \max }$ is routine in endurance sports. ${ }^{6}$

However, in team sports, due to the number of players, the economic cost of laboratory tests and the discontinuous nature of play, field tests to assess players' endurance performance (e.g., $\mathrm{VO}_{2 \max }$ ) have been more widely adopted. ${ }^{7-11}$ Because of the intermittent nature of the team sports, intermittent tests have achieved a great popularity during the last years to assess players' endurance performance. ${ }^{9,11-19}$ The most widely known and used intermittent test is the Yo-Yo intermittent recovery test level 1 (YYIR1). During this test players run 20-m shuttle runs at progressively increasing speeds with briefs recovery periods (10-s) between the runs. ${ }^{8}$ Different studies have successfully analyzed the validity and reliability of the YYIR1 to measure soccer players' endurance $8,11,12,20$. Although, the YYIR1 was developed to assess soccer players' endurance performance, it has been used in different team sports. ${ }^{17,21}$

The test most widely used to assess the volleyball players' endurance has been the $20-\mathrm{m}$ shuttle run test. ${ }^{22,23}$ Although, this test has been previously validated to estimate $\mathrm{VO}_{2 \max }{ }^{7}$ the type of exercise is relatively continuous, which moves away from the highly intermittent effort that volleyball players perform during competition. ${ }^{23-25}$ It has been recently reported that the YYIR1 has been used to assess the endurance performance in volleyball female players. ${ }^{18}$ Although, this test is more specific than the 20 -m shuttle run test, it has never been validated in volleyball. Moreover, the type of displacement performed during the test is not very specific to volleyball. To our knowledge, no specific test to assess volleyball players' endurance has been validated. Therefore the aim of this study was to analyze the concurrent and construct validity of a volleyball intermittent endurance test, and additionally to determinate the test-retest reliability, and sensitivity of this test for monitoring the fitness changes.

\section{Methods}

\section{Subjects}

Seventy one Spanish volleyball players from different competitive levels participated in this study (mean [range], age 19.7 y [16-29], height $177.8 \mathrm{~cm}$ [155.0-201.0], and body mass $71.6 \mathrm{~kg}$ [45.8-96.5]). The sample of players consisted of junior female players ( $N=20$, non-elite level), third division female players $(N=16$, sub-elite level), fourth division male players $(N=25$, sub-elite level) and second division male players $(N=13$, elite level). All of them had competition experience of 11 y (2-19) and a high competitive level within their divisions. Players from the second division belonged to the Junior 
103 National Team and trained 6 times per week $\left(\sim 3.5 \mathrm{~h} \cdot \mathrm{d}^{-1}\right)$, the other teams trained 3 times 104 per week $\left(\sim 2 \mathrm{~h} \cdot \mathrm{d}^{-1}\right)$. All teams competed once per week during the regular season. 105 Written informed consent was obtained from all subjects (or their parents) before starting 106 the study. The protocol was approved by the local Ethics Committee, and conformed to 107 principles identified in the Declaration of Helsinki.

108

109

110

111

112

113

114

115

116

117

118

119

120

121

122

123

124

125

126

127

128

129

130

131

132

133

134

135

136

137

138

139

140

141

\section{Procedures}

During the pre-season the subjects performed a treadmill exercise test with gas exchange measurement (GXT) and a volleyball intermittent endurance test (VIET). The tests were administered in a random order. The tests were separated by 7 days and performed at the same time of day under similar environmental conditions $\left(20-25{ }^{\circ} \mathrm{C}, 40-45 \%\right.$ relative humidity). To analyze the test-retest reliability, 31 of the players performed an additional VIET within 7 days of the first test. Finally, to test the sensitivity of VIET to training improvements, 28 players repeated the GXT and VIET at the end of the competitive season. All tests were preceded by a 10 min warm-up period of running at $7-10 \mathrm{~km} \cdot \mathrm{h}^{-1}$ and free stretching for $5 \mathrm{~min}$. During the $24 \mathrm{~h}$ prior to testing sessions the players were instructed to avoid strenuous training sessions and to follow a carbohydrate-rich diet. Prior to start the study all subjects had carried out a test familiarization session.

Graded Exercise Test. The test was performed on a treadmill $(\mathrm{h} / \mathrm{p} / \mathrm{cosmos}$ pulsar, $\mathrm{h} / \mathrm{p} /$ cosmos sports \& medical GMBH, Nussdorf-Traunstein, Germany) with a $1 \%$ slope. ${ }^{26}$ The initial speed was $6 \mathrm{~km} \cdot \mathrm{h}^{-1}$ and was increased $1 \mathrm{~km} \cdot \mathrm{h}^{-1}$ every minute until volitional exhaustion. The maximal speed was determined as the highest speed maintained for a complete stage plus the interpolated speed from incomplete stages. ${ }^{6}$ The HR response was measured telemetrically every 5-s (Polar Vantage NV, Polar Electro Oy, Finland) and respiratory gas exchange was continuously measured breath-by-breath (Medisoft Ergocard, Medisoft Group, Sorinnes, Belgium). $\mathrm{VO}_{2 \max }$ and maximal HR were recorded as the highest values obtained for the last 30 -s period before exhaustion. The ventilatory (VT) and respiratory compensation (RCT) thresholds were identified according to the criteria of Davis: ${ }^{27}$ increase in both $\mathrm{VE} \cdot \mathrm{VO}_{2}{ }^{-1}$ and $\mathrm{PETO}_{2}$ with no concomitant increase in VE$\cdot \mathrm{VCO}_{2}^{-1}$ for $\mathrm{VT}$, and an increase in both VE$\cdot \mathrm{VO}_{2}^{-1}$ and $\mathrm{VE} \cdot \mathrm{VCO}_{2}{ }^{-1}$ and a decrease in $\mathrm{PETCO}_{2}$ for RCT.

Volleyball Intermittent Endurance Test. The subjects ran around a circuit, marked by cones, on the volleyball court using different specific volleyball movements (Figure 1). The test consisted of repeated runs of $177 \mathrm{~m}$ at a progressively increased speed controlled by audio bleeps (TIVRE-Voley, DSD Inc., León, Spain). The players completed 3 laps (59 $\mathrm{m}$ per lap) of the circuit for each running stage. Between each stage the subjects had a 30$\mathrm{s}$ passive rest period. The test started at $6 \mathrm{~km} \cdot \mathrm{h}^{-1}$ and the speed increased $0.6 \mathrm{~km} \cdot \mathrm{h}^{-1}$ every running stage until volitional exhaustion. The test ended when the players twice failed to reach the cone in time, ${ }^{8}$ at that moment the distance covered was measured. As in the incremental exercise test, the maximal speed was obtained by interpolating the speed from the incomplete stage. The HR response was measured telemetrically every 5-s throughout the test (Polar Team², Polar Electro Oy, Kempele, Finland).

148 
149

150

151

152

153

154

155

156

157

158

159

160

161

162

163

164

165

166

167

168

169

170

171

172

173

174

175

176

177

178

179

180

181

182

183

184

185

186

187

188

189

190

191

192

193

194

\section{Statistical analyses}

The results are expressed as mean \pm standard deviation (SD). The assumption of normality was verified using the Shapiro-Wilk test. A paired Student's $t$ test was applied to establish differences between the maximal HR and speed obtained during the GXT and VIET. The same analysis was used to compare the VIET test-retest results and to assess changes in outcomes between the tests performed from the pre-season to the end of the season. Analysis of variance (ANOVA) was used to compare the variables according to playing level and gender. When a significant $\mathrm{F}$ value was found, Bonferroni's test was used to establish significant differences between means. The magnitude of difference was expressed as a standardized mean difference (ES). Cohen's $d$ and partial eta squared $\left(\eta^{2}\right)$ were calculated as indicators of ES when the Student's t and ANOVA were used, respectively. Cohen's d values of $<0.20,0.20-0.50,0.51-0.80$ and $>0.80$ were rated trivial, small, moderates, and large effects, respectively. ${ }^{28}$ The relationship between variables was determined using Pearson correlation coefficient $(r)$. Relative reliability and concordance between measures were assessed using the intraclass correlation coefficient (ICC). Values of $P<0.05$ were considered statistically significant. The absolute reliability was assessed by calculating the typical error of measurement (TE) and the coefficient of variation (CV; TE expressed as a percentage). The $r$, ICC, TE and CV were accompanied with $90 \%$ CI. Additionally, Bland-Altman plots for assessing agreement between the maximal HR in GXT and VIET and between the maximal HR and distance covered during the two VIET trials was used. The smallest worthwhile change (SWC) in VIET for maximal HR and distance was calculated. ${ }^{28}$ The SWC was compared with the TE to analyze the VIET usefulness. The test was rated as "good", "OK" or "marginal" when the TE was below, similar or higher than the SWC, respectively. ${ }^{28}$ SPSS+ V.19.0 statistical software (Chicago, Illinois, USA) was used.

\section{Results}

The mean measured $\mathrm{VO}_{2 \max }$ and distance covered in the VIET were $47.0 \pm 8.5 \mathrm{ml} \cdot \mathrm{kg}^{-}$ ${ }^{1} \cdot \mathrm{min}^{-1}$ and $1643.2 \pm 344.0 \mathrm{~m}$, respectively. Higher $(P<0.001)$ maximal speed was obtained during GXT $\left(15.5 \pm 2.0 \mathrm{~km} \cdot \mathrm{h}^{-1}\right)$ than during VIET $\left(11.3 \pm 1.3 \mathrm{~km} \cdot \mathrm{h}^{-1}\right)$. Significant $(P<0.001)$ relationships between VIET performance $($ i.e., $\mathrm{m})$ and GXT maximal speed $(r=0.78,0.69-0.85)$ and $\mathrm{VO}_{2 \max }(r=0.74,0.64-0.82)$ were observed. Moreover, the VIET performance was significantly $(p<0.001)$ related to the velocity at VT $(r=0.62,0.48-0.73)$ and RCT $(r=0.76,0.66-0.83)$. The maximal HR in both tests was similar $(196 \pm 8$ vs. $195 \pm 9$ bpm for VIET and GXT, respectively; ES $=0.11$, trivial). A significant $(P<0.001)$ correlation and ICC between HR on both test was found $(r=0.85,0.78-0.90$ and ICC $=0.91,0.87-0.94)$. The mean bias was $1 \pm 5$ and the $95 \%$ limits of agreement were $-9-11$. TE and CV of maximal HR was 4 bpm (3-5) and 1.9\% (1.7-2.2), respectively.

There were no significant differences between the distance covered $(1542.1 \pm 338.1 \mathrm{vs}$. $1567.1 \pm 358.2 \mathrm{~m}, \mathrm{ES}=0.08$, trivial $)$ and maximal HR $(199 \pm 9$ vs. $197 \pm 8 \mathrm{bpm}$; ES $=$ 0.18 , trivial) during the repeated VIET trials. Significant $(P<0.001)$ relationships and ICC were found $(r=0.95$ [0.91-0.97] \& ICC $=0.96$ [0.91-0.97] and $r=0.91$ [0.84-0.95] 
$195 \&$ ICC $=0.91[0.84-0.95]$ for distance and maximal HR, respectively). The results of the 196 Bland-Altman plots are shown in the Figure 2. This analysis demonstrated a good 197 concordance between trial 1 and trial 2. TE and CV for distance and maximal HR were $69.6 \mathrm{~m}(57.8-89.0) \& 4.4 \%(3.6-5.6)$ and $2 \mathrm{bpm}(2-4) \& 1.1 \%$ (1.3-2.0), respectively. According to the SWC the VIET was rated as "OK" for distance (69.7 $\mathrm{m}$ [57.7-88.7]) and maximal HR (2 bpm [1-2]). No significant difference between HR response during the two consecutive trials was found.

201

202

203

204

205

206

207

208

209

210

211

212

213

214

215

216

217

218

219

220

221

222

223

224

225

226

227

228

229

230

231

232

233

234

235

236

237

238

239

240

The VIET performance increased significantly $(P<0.001)$ with performance level (Table $1)$ and it was sensitive to fitness changes across the season $(1458.8 \pm 343.5 \mathrm{vs} .1581 .1 \pm$ $334.0 \mathrm{~m}, P<0.01$; ES $=0.38$, small $)$. Lower $(P<0.05)$ submaximal HR during the VIET performed at the pre-season versus the end of the season were observed (Figure 3). However, data from GXT were sensitive to gender (Table 1). No changes between the GXT performed at the beginning and the end of the season were evident (Table 2).

\section{Discussion}

The principal finding of the present study is that the VIET is valid and reliable to assess volleyball players' aerobic fitness. Additionally, this test was shown to be sensitive to the seasonal changes and differences between performance level. The VIET performance and $\mathrm{VO}_{2 \max }$ were significantly related $(r=0.74)$, with $55 \%$ of shared variance. This correlation was similar to those showed in previous studies with the YYIR1 $(r=0.71-$ 0.77 ) in soccer ${ }^{8,9,11,12}$ and basketball ${ }^{21}$ players. Our results, as previous findings, suggest that other physiological variables, in addition to $\mathrm{VO}_{2 \max }$, may affect intermittent test performance. Thus, in agreement with others, ${ }^{9,11,16}$ we showed relationships between VIET performance and other submaximal aerobic variables such as VT and RCT. In the same way, players' recovery capacity seems to influence the intermittent tests performance. ${ }^{10}$ Correlations between these tests and repeated sprint ability ${ }^{12}$ and specific anaerobic test decrement after an experimental-game in basketball players ${ }^{21}$ have been found.

In addition to the aerobic fitness, the anaerobic contribution to the intermittent tests performance plays an important role. ${ }^{8,11}$ Although this contribution was not measured in the present study, it may be hypothesized that was relevant for the VIET performance due to its intermittent nature and specific movements performed. The continuous deceleration-acceleration phases during the changes of direction performed throughout the VIET circuit presumably involve anaerobic metabolism. Previous research reported a higher anaerobic contribution during intermittent vs. continuous exercise. ${ }^{13}$ Furthermore, the effect of lower limbs' explosive strength on intermittent tests performance has been

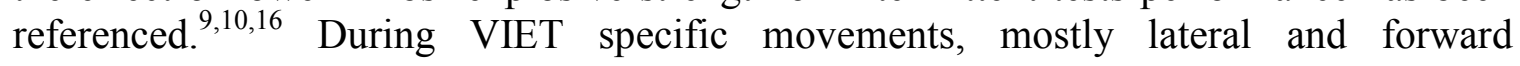
displacements, with the knees semi-flexed, may deteriorate the running efficiency. Foster et al. $^{29}$ demonstrated a restricted muscle blood flow during speed skating with comparable knee angles. They reported a greater $\mathrm{O}_{2}$ desaturation and accelerated blood lactate accumulation in low versus high position. Supporting this idea, Besson et al. ${ }^{15}$ found in hockey players higher blood lactate during a specific than non-specific 30-15 intermittent test in spite of similar maximal speed. 
242 The distance covered and maximal HR may be reliably measured using the VIET.

243 Differences between trials for distance and maximal HR were rated as trivial. Moreover, 244 a high ICC and small CV were obtained for both variables $(0.95 \& 4.4 \%$ and $0.91 \&$ $2451.1 \%$, respectively). These results are in accordance with CV found previously for the 246 distance covered $(3-7.5 \%)^{8,19,20}$ and maximal HR $(0.6-1 \%)^{8,16}$ in different intermittent 247 field-based tests. The TE obtained for the distance covered was similar $(\sim 70 \mathrm{~m})$ to the 248 SWC, so that the VIET was rated as "OK" to detect changes in the players performance. Although, a higher rating (i.e., "good") would be expected with a greater players' familiarization with the test. ${ }^{28}$ Recently, a test-retest reliability study showed a TE decrement of $\sim 13 \%$ (i.e., $15 \mathrm{~m}$ ) when three intermittent tests were completed in three consecutive weeks. ${ }^{20}$ From a practical point of view, changes approximately of half stage $(\sim 88 \mathrm{~m})$ might be considered as meaningful to assess the players' improvements. However, an approach using more precise (i.e., 95\% CI) might be performed, calculating the minimum difference to be considered "real". Thus, any change on repeated test $\geq 192 \mathrm{~m}$ (approximately 1 stage) is considered real. On the other hand, based on the VIET validity and reliability of assessing maximal HR, this may be a useful tool to control and prescribe the endurance training in volleyball players. ${ }^{24}$

The results showed that VIET was sensitive to assess differences between players' level (Table 1). However, the aerobic performance assessed by GXT was similar within each gender (Table 1). Therefore, we think that the differences found in the VIET performance were mainly due to higher specific aerobic and anaerobic performance in players with higher playing level. This finding is in agreement with previous studies, ${ }^{11,12}$ which found a higher specific endurance performance in soccer players of higher playing level, whilst $\mathrm{VO}_{2 \max }$ was similar. It have been suggested that a higher adaptation of these players to performing high-intensity intermittent exercise could be the cause of this result. ${ }^{11}$ Therefore, it seems reasonable to expect that the higher level players of this study had a better ability to perform high-intensity exercises due to already performing higher intensity during training sessions and matches. ${ }^{12}$ In addition, non-elite female players were inexpert and their training was based on improving their technical skills. Previously, we have shown that these training sessions only require low-moderate exercise intensity. ${ }^{24}$ Therefore, technical-based training programs are unlikely to have an effect on players' physiological capacity. ${ }^{22}$

Finally, the VIET was shown to be useful to assess seasonal changes in players' performance. Players improved their performance $8.4 \%$ across the season. This change was smaller than found in the Yo-Yo IR1 in soccer and futsal players during the preseason (15-35\%). ${ }^{8,14,17}$ Although, it was in accordance with changes obtained in 30-15 intermittent fitness test performance after 8 -wk of pre-season $(7 \%) .{ }^{14}$ We believe that the main determinant of theses test might differ slightly due to the different protocols used. However, the difference in the change between tests may be similar when the standardized differences are used instead of percentage of change. ${ }^{14}$ On the other hand, subject were not assessed at the beginning of the pre-season, which might limit players' improvements. It has been found a negative correlation between the players' initial fitness and performance change. ${ }^{17}$ Although, greater improvements could be expected 
287

288

289

290

291

292

293

294

295

296

297

298

299

300

301

302

303

304

305

306

307

308

309

310

311

312

313

314

315

316

317

318

319

320

321

322

323

324

325

326

327

328

329

330

331

332

after 5 months of training, it has been shown that in-season training does not lead to major changes. ${ }^{8}$ Characteristics of training performed in-season seem to have an important role in this fact. The mean training load is reduced and more emphasis is placed on technical-tactical training instead of physical capacity sessions. ${ }^{24}$ Coaches in these sessions often use small-side games to perform a more specific training. These are formed by specific high-intensity movements, such as sprints and jumps, which reproduce the physiological demands of volleyball matches. ${ }^{23}$ Therefore, the $\mathrm{VO}_{2 \max }$ might reasonably remained unchanged across the season. Similar finding have been reported earlier by Hakkinen ${ }^{25}$ in female volleyball players. Hakkinen ${ }^{25}$ like others ${ }^{22,23}$ mainly have reported changes in explosive strength performance in volleyball players. A noteworthy finding was the lower submaximal HR found during the VIET performed at the end than the beginning of the season (Figure 3). This pattern has been previously observed in team players after a training period ${ }^{8,17}$ and it has been showed that is lower according to the players' level. ${ }^{12}$ Collectively, these results suggest that the submaximal HR may be used to monitor training adaptation in volleyball players.

\section{Practical Applications}

Our findings support the use of the VIET to assess the volleyball players' aerobic fitness. This field test can be a simple and practical tool for coaches, since it does not require the use of sophisticated equipment and may be used to assess multiple players simultaneously. The VIET is appropriate to establish differences between the players' performance according to their playing level. In addition, the VIET was shown useful to identify seasonal changes. Based on the TE and SWC values obtained in this study, we suggest that a changes of approximately 1 stage (between 88-192 m) may be considered as an improvement or deterioration on the players' performance. Using the VIET, instead of others intermittent tests, allows a more specific approach to the movements performed by the volleyball players. Finally, the VIET has potential training applications. Coaches may use the VIET circuit to perform specific endurance training, selecting a target intensity. On the other hand, the validity and reliability shown to estimate the maximal HR enable coaches to assess this parameter to monitor and control the training process. The submaximal HR analyzed in the test may be taken into consideration to monitor players' training adaptation. This may allow coaches to perform a submaximal test version to control the training process routinely.

\section{Conclusions}

In conclusion, the results of this study suggest that VIET may be considered as a valid and reliable test to assess the aerobic endurance in volleyball players. Likewise, this test has a high construct validity, since it was sensitive to fitness differences according to the playing level. In addition, VIET is sensitive to detect seasonal changes in the physical fitness of volleyball players. Further studies should analyze the relationships between VIET performance and different parameters of match-performance.

\section{References}


333

334

335

336

337

338

339

340

341

342

343

344

345

346

347

348

349

350

351

352

353

354

355

356

357

358

359

360

361

362

363

364

365

366

367

368

369

370

371

372

373

374

375

376

377

378

1. Hill AV, Lupton H. Muscular exercise, lactic acid, and the supply and utilization of oxygen. Q J Med. 1923;16:135-171.

2. Taylor HL, Buskirk E, Henschel A. Maximal oxygen intake as an objective measure of cardio-respiratory performance. J Appl Physiol. 1955;8:73-80.

3. Saltin B, Astrand PO. Maximal oxygen uptake in athletes. J Appl Physiol. 1967;23:353-358.

4. Mcfarlane DJ. Automated metabolic gas analysis systems. A review. Sports Med. 2001;31:841-861.

5. Joyner MJ, Coyle EF. Endurance exercise performance: the physiology of champions. J Physiol. 2008;586:35-44.

6. Kuipers H, Verstappen FT, Keizer HA, Geurten P, van Kranenburg G. Variability of aerobic performance in the laboratory and its physiological correlates. Int $J$ Sports Med. 1985;6:197-201.

7. Léger LA, Lambert J. A Maximal multistage 20 -m shuttle run test to predict $\mathrm{VO}_{2 \max }$. Eur J Appl Physiol. 1982;49:1-12.

8. Krustrup P, Mohr M, Amstrup V, Rysgaard T, Johansen J, Steensberg A, Pedersen PK, Bangsbo J. The Yo-Yo Intermittent Recovery Test: Physiological response, reliability, and validity. Med Sci Sports Exerc. 2003;35:697-705.

9. Castagna C, Impellizzeri FM, Belardinelli R, Abt G, Coutts A, Chamari K, D'Ottavio S. Cardiorespiratory responses to yo-yo intermittent endurance test in nonelite youth soccer players. J. Strength Cond. Res. 2006;20:326-330.

10. Buchheit $\mathrm{M}$. The 30-15 intermittent fitness test: accuracy for individualizing interval training of young intermittent sport players. J Strength Cond Res. 2008;22:365-374.

11. Rampinini E, Sassi A, Azzalin A, Castagna C, Menaspà P, Carlomagno D, Impellizzeri FM. Physiological determinants of Yo-Yo intermittent recovery tests in male soccer players. Eur J Appl Physiol. 2010;108:401-409.

12. Ingebrigtsen J, Bendiksen M, Randers MB, Castagna C, Krustrup P, Holtermann A. Yo-Yo IR2 testing of elite and sub-elite soccer players: performance, heart rate response and correlations to other interval tests. J Sports Sci. 2012;30:1337-1345.

13. Buchheit M, Al Haddad H, Millet GP, Lepretre PM, Newton M, Ahmaidi S. Cardiorespiratory and cardiac autonomic responses to 30-15 Intermittent Fitness Test in team sport players. J Strength Cond Res. 2009;23:93-100.

14. Buchheit M, Rabbani A. The 30-15 Intermittent Fitness Test versus the Yo-Yo Intermittent Recovery Test Level 1: relationship and sensitivity to training. Int $J$ Sports Physiol Perform. 2014;9:522-524.

15. Besson C, Buchheit M, Praz M, Dériaz O, Millet GP. Cardiorespiratory responses to the 30-15 intermittent ice test. Int J Sports Physiol Perform. 2013;8:173-180.

16. Da Silva JF, Guglielmo LG, Carminatti LJ, De Oliveira FR, Dittrich N, Paton CD. Validity and reliability of a new field test (Carminatti's test) for soccer players compared with laboratory-based measures. J Sports Sci. 2011;29:1621-1628.

17. de Freitas VH, Pereira LA, de Souza EA, Leicht AS, Bertollo M, Nakamura FY. Sensitivity of the Yo-Yo Intermittent Recovery Test and cardiac autonomic responses to training in futsal players. Int J Sports Physiol Perform. 2015;10:553538.

18. Kilic-Toprak E, Yapici A, Kilic-Erkek O, Koklu Y, Tekin V, Alemdaroglu U, BorKucukatay M. Acute effects of Yo-Yo intermittent recovery test level 1 (Yo-YoIR1) 
379

380

381

382

383

384

385

386

387

388

389

390

391

392

393

394

395

396

397

398

399

400

401

402

403

404

405

406

407

408

409

on hemorheological parameters in female volleyball players. Clin Hemorheol Microcirc. 2015;16;60:191-199.

19. Vaquera A, Villa JG, Morante JC, Thomas G, Renfree AJ, Peters DM. Validity and test-retest reliability of the TIVRE-Basket test for the determination of aerobic power in elite male basketball players. J Strength Cond Res. 2016;30:584-587.

20. Deprez D, Fransen J, Lenoir M, Philippaerts R, Vaeyens R. The Yo-Yo intermittent recovery test level 1 is reliable in young high-level soccer players. Biol Sport. 2015;32:65-70.

21. Castagna C, Impellizzeri FM, Rampinini E, D'Ottavio S, Manzi V. The Yo-Yo intermittent recovery test in basketball players. J Sci Med Sport. 2008;11:202-208.

22. Gabbet T, Georgieff B, Anderson S, Cotton B, Savovic D, Nicholson L. Changes in skill and physical fitness following training in talent-identified volleyball players. $J$ Strength Cond Res. 2006;20:29-35.

23. Gabbet, T. Do skill-based conditioning games offer a specific training stimulus for junior elite volleyball players? J Strength Cond Res. 2008;22:509-517.

24. Rodríguez-Marroyo JA, Medina J, García-López J, García-Tormo JV, Foster C. Correspondence between training load executed by volleyball players and the one observed by coaches. $J$ Strength Cond Res. 2014;28:1588-1594.

25. Häkkinen $\mathrm{K}$. Changes in physical fitness profile in female volleyball players during the competitive season. J Sports Med Phys Fitness. 1993;33:223-232.

26. Jones AM, Doust JH. A $1 \%$ treadmill grade most accurately reflects the energetic cost of outdoor running. Sports Sci. 1996;14:321-327.

27. Davis JA. Anaerobic threshold: a review of the concept and directions for future research. Med Sci Sports Exerc. 1985;17:6-18.

28. Hopkins WG. How to interpret changes in an athletic performance test. Sportsci 2004;8:1-7.

29. Foster C, Rundell KW, Snyder AC, Stray-Gundersen J, Kemkers G, Thometz N, Broker J, Knapp E. Evidence for restricted muscle blood flow during speed skating. Med Sci Sports Exerc. 1999;31:1433-1440.

30. Weir JP. Quantifying test-retest reliability using the intraclass correlation coefficient and the SEM. J Strength Cond Res. 2005;19:231-240. 


\section{Tables}

Table 1. Volleyball intermittent endurance (VIET) and graded exercise test (GXT) results (mean $\pm S D$ ) according to the subjects' 414 performance level.

\begin{tabular}{|c|c|c|c|c|c|c|}
\hline & & \multicolumn{2}{|c|}{ Female players } & \multicolumn{2}{|c|}{ Male players } & \multirow{2}{*}{$\eta^{2}$} \\
\hline & & Non-elite & Sub-elite & Sub-elite & Elite & \\
\hline VIET & Maximal speed $\left(\mathrm{km} \cdot \mathrm{h}^{-1}\right)$ & $9.3 \pm 0.7^{* \dagger t}$ & $10.5 \pm 0.6 \dagger t$ & $11.5 \pm 0.7 \ddagger$ & $12.4 \pm 0.6$ & 0.67 \\
\hline \multirow{4}{*}{$G X T$} & $\mathrm{VO}_{2 \max }\left(\mathrm{ml} \cdot \mathrm{kg}^{-1} \cdot \mathrm{min}^{-1}\right)$ & $35.1 \pm 2.7 \dagger t$ & $38.2 \pm 5.1 \dagger t$ & $52.5 \pm 5.7$ & $49.5 \pm 3.9$ & 0.70 \\
\hline & Speed at VT $\left(\mathrm{km} \cdot \mathrm{h}^{-1}\right)$ & $8.0 \pm 0.5+\dagger$ & $8.3 \pm 0.6+t$ & $9.9 \pm 1.0$ & $10.3 \pm 0.9$ & 0.55 \\
\hline & $\mathrm{VO}_{2}$ at $\mathrm{RCT}\left(\mathrm{ml} \cdot \mathrm{kg}^{-1} \cdot \mathrm{min}^{-1}\right)$ & $29.8 \pm 2.7 \dagger t$ & $33.4 \pm 4.6+t$ & $44.4 \pm 5.4$ & $43.0 \pm 2.9$ & 0.63 \\
\hline & Speed at RCT $\left(\mathrm{km} \cdot \mathrm{h}^{-1}\right)$ & $10.5 \pm 0.5+t$ & $10.8 \pm 0.9 \dagger+$ & $13.0 \pm 1.1$ & $13.8 \pm 0.8$ & 0.69 \\
\hline
\end{tabular}

415 VT, ventilatory threshold; RCT, respiratory compensation threshold; $\eta^{2}$, effect size in terms of partial eta squared. *, Significant

416 difference with Female Sub-elite players $(p<0.05)$. $\dagger$, Significant difference with male Sub-elite players $(p<0.05)$. $\ddagger$, Significant 417 difference with male Elite players $(p<0.05)$. 
Table 2. Graded exercise test data (mean $\pm S D$ ) at the beginning and end of the volleyball season.

\begin{tabular}{|c|c|c|c|}
\hline & Pre-test & Post-test & ES (rating) \\
\hline Maximal speed $\left(\mathrm{km} \cdot \mathrm{h}^{-1}\right)$ & $15.3 \pm 1.9$ & $15.4 \pm 2.1$ & 0.05 (trivial) \\
\hline $\mathrm{VO}_{2 \max }\left(\mathrm{ml} \cdot \mathrm{kg}^{-1} \cdot \min ^{-1}\right)$ & $47.6 \pm 8.8$ & $45.8 \pm 9.4$ & 0.20 (small) \\
\hline Maximal HR (bpm) & $196 \pm 7$ & $197 \pm 7$ & 0.15 (trivial) \\
\hline Speed at VT $\left(\mathrm{km} \cdot \mathrm{h}^{-1}\right)$ & $9.5 \pm 1.0$ & $9.7 \pm 1.4$ & 0.17 (trivial) \\
\hline $\mathrm{VO}_{2}$ at $\mathrm{VT}\left(\mathrm{ml} \cdot \mathrm{kg}^{-1} \cdot \mathrm{min}^{-1}\right)$ & $31.7 \pm 4.9$ & $31.6 \pm 6.4$ & 0.02 (trivial) \\
\hline HR at VT (bpm) & $163 \pm 9$ & $163 \pm 8$ & 0.10 (trivial) \\
\hline Speed at RCT $\left(\mathrm{km} \cdot \mathrm{h}^{-1}\right)$ & $12.4 \pm 1.6$ & $12.2 \pm 1.6$ & 0.13 (trivial) \\
\hline $\mathrm{VO}_{2}$ at $\mathrm{RCT}\left(\mathrm{ml} \cdot \mathrm{kg}^{-1} \cdot \mathrm{min}^{-1}\right)$ & $41.1 \pm 8.1$ & $38.8 \pm 7.5$ & 0.30 (small) \\
\hline $\mathrm{HR}$ at $\mathrm{RCT}(\mathrm{bpm})$ & $181 \pm 9$ & $181 \pm 8$ & 0.05 (trivial) \\
\hline
\end{tabular}




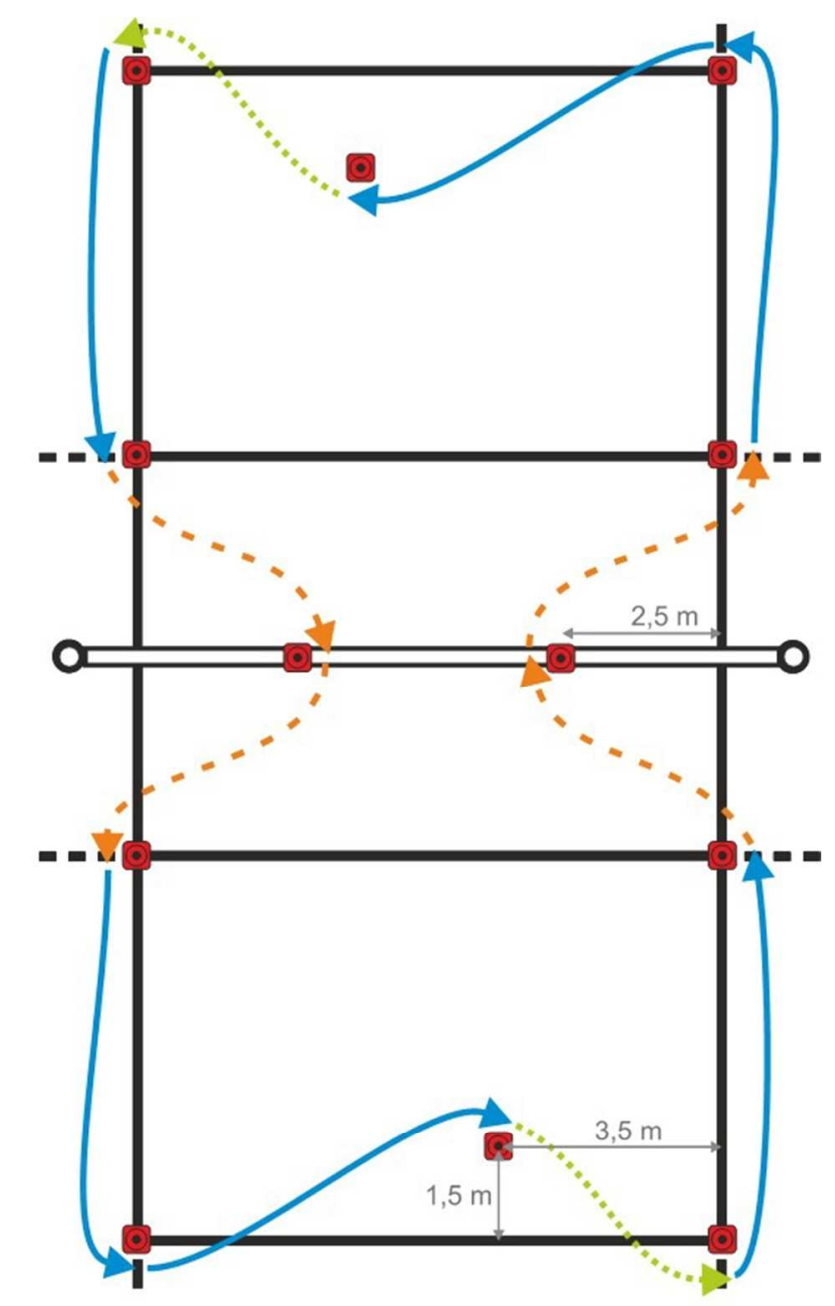

Forward displacement

Lateral displacement

Backward displacement

Figure 1. Circuit performed by players during the test. $93 \times 180 \mathrm{~mm}(150 \times 150 \mathrm{DPI})$ 

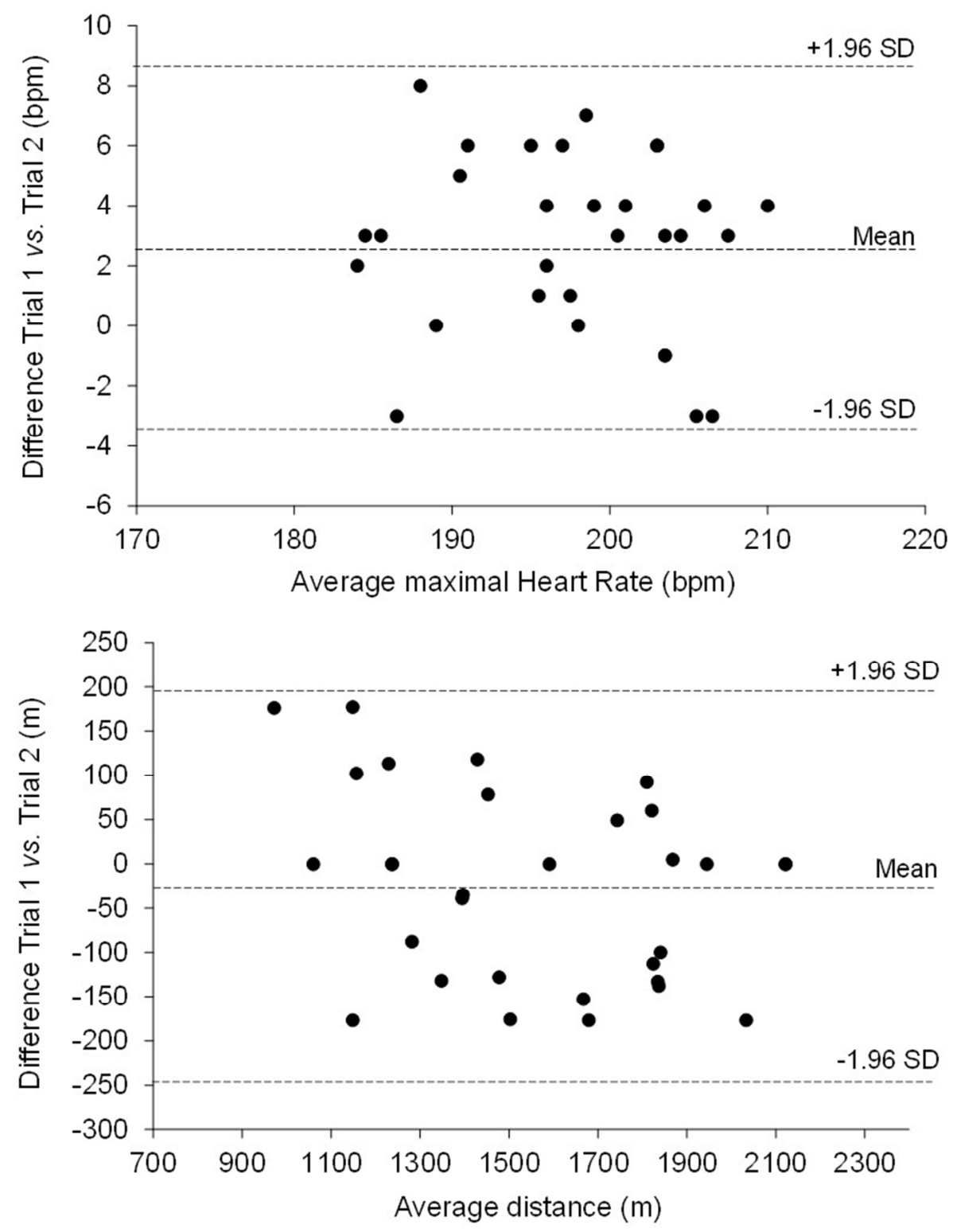

Figure 2. Bland-Altman plots with estimated bias of the differences in maximal heart rate and total distance covered between trail 1 and 2 .

$135 \times 176 \mathrm{~mm}(150 \times 150 \mathrm{DPI})$ 


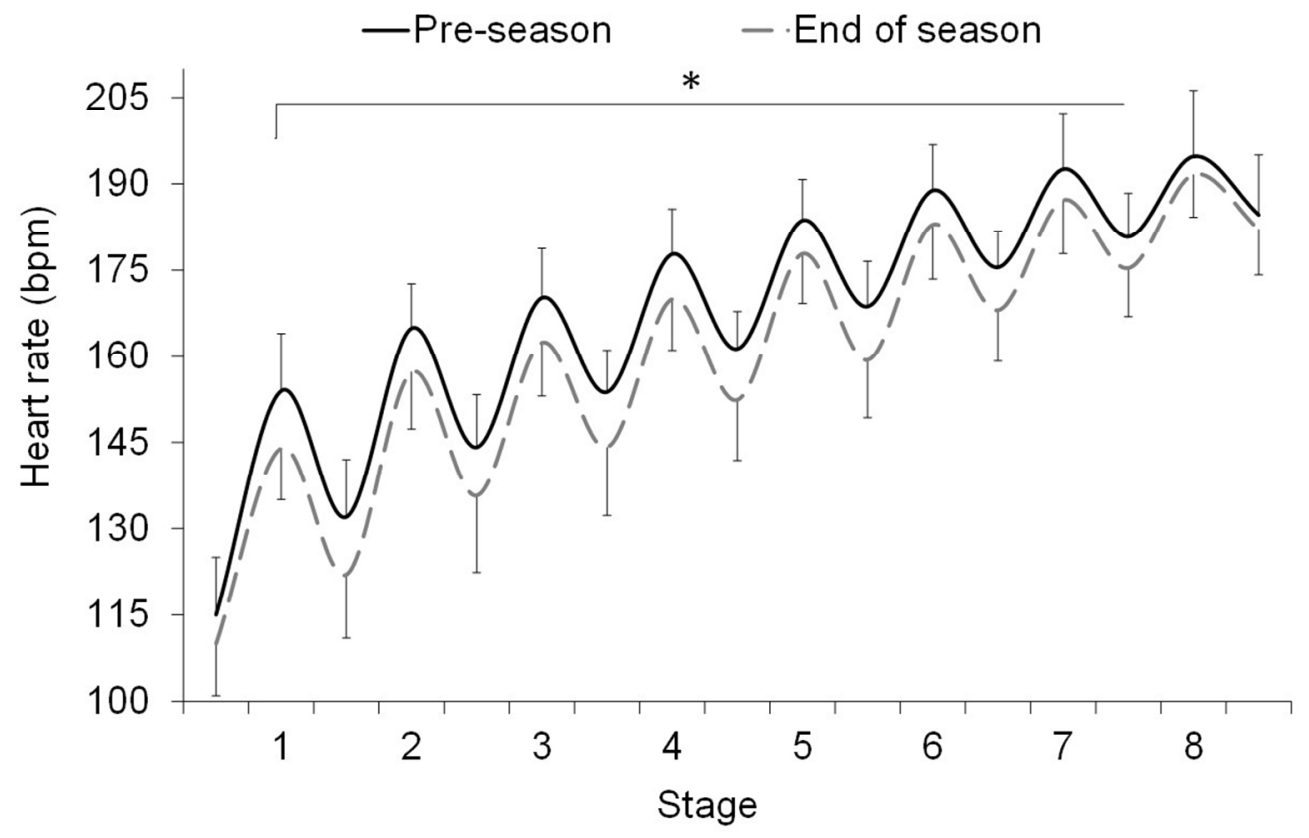

Figure 3. Heart rate pattern during the volleyball intermittent endurance test performed during the preseason and at the end of the season.

$204 \times 133 \mathrm{~mm}(150 \times 150 \mathrm{DPI})$ 